\title{
Successful visual rehabilitation after neonatal penetrating keratoplasty
}

\author{
Richard W Hertle, Stephen E Orlin
}

\begin{abstract}
Background-Penetrating keratoplasty in infancy and childhood has traditionally met with limited visual success due to a combination of unique physiology and technical problems in this patient population. With the advances in microsurgical instrumentation, corneal preservation, and visual developmental physiology ophthalmologists are finding increasing indications for penetrating keratoplasty in the childhood population. The long term results of neonatal penetrating keratoplasty in two patients with unilateral congenital corneal opacification are reported. Methods-Penetrating keratoplasty was performed on one eye in each of two infants within the first 3 weeks of life. Amblyopia treatment and optical therapy have been continued since surgery.

Results-After 6 years both grafts have remained clear. One patient developed the infantile esotropia syndrome. Visual development using Snellen optotypes is age normal for both transplanted eyes.

Conclusions-Penetrating keratoplasty when combined with optical correction and amblyopia therapy may restore and preserve vision in selected patients with congenital corneal opacification if performed in the neonatal period.

(Br F Ophthalmol 1997;81:644-648)
\end{abstract}

Penetrating keratoplasty has a high success rate in the adult population. ${ }^{1}$ Technical challenges, an exuberant inflammatory response, amblyopia, rejection, glaucoma, and treatment compliance in neonatal and infant transplantation have led some authors not to recommend surgery for unilateral corneal opacities..$^{2-8}$

If the visual axis is congenitally obstructed (ptosis, corneal opacification, cataract, vitreous haemorrhage, etc) and left untreated irreversible changes take place in the visual system serving that eye. ${ }^{9}{ }^{10}$ The lateral geniculate and striate cortex suffer from anatomical and physiological maldevelopment. ${ }^{11}$ Various visual functions (for example, grating acuity, recognition acuity, contrast sensitivity, stereopsis, accommodation, fusion, colour vision) may have different 'sensitive periods' in development. ${ }^{12}{ }^{12}$ In human infants 1 week of monocular occlusion can result in severe amblyopia at the peak period of susceptibility. ${ }^{13-15}$ Also in humans, neither congenital cataracts nor congenital esotropia produce permanent loss of acuity if treated before 2 months of age. ${ }^{15-17}$
As a result of clinical, behavioural, electrophysiological, and anatomical studies of congenital obstruction of vision clinicians now are aggressive at early establishment of a clear and optically corrected visual axis. Surgical and optical rehabilitation is performed within 1 week of diagnosis in neonates and infants. ${ }^{18}$ Amblyopia is treated with occlusion of the sound eye. This method of treatment has improved visual results in infants with congenital cataracts. ${ }^{18}$ We have used these treatment principles in the management of two patients with congenital corneal opacification with good results.

\section{Methods}

A retrospective analysis of clinical information was obtained on the two patients who are the subjects in this report. Clinical data included all information obtained at surgery and outpatient examinations. These data are summarised below.

\section{Patients}

CASE 1

JG was born 1 month premature on 23 February 1990 to a 24-year-old woman with a known history of mental retardation and strabismus who denied any use of drugs or health problems during her pregnancy. JG's medical problems included tetralogy of Fallot, nocturnal seizures with an asymmetric Todd's paralysis, and associated asymmetrically abnormal electroencephalogram and developmental delay. She was first evaluated by us at 10 days old, referred because of an abnormal red reflex in both eyes. Examination at that time revealed objection to light in both eyes. Both corneas had obvious opacification extending from the inferior-nasal portion of the limbus in a wedge shape with obscuration of the pupil on the right and up to the border of the pupil on the left. There was no evidence of corneal oedema, thinning, or vascularisation in either eye (Fig 1). Her cycloplegic refraction was +1.75 sphere in both eyes The iris appeared normal and after dilatation of the pupils the lenses, vitreous, and retina appeared healthy.

On 14 March 1990 at 19 days of age a penetrating keratoplasty was performed on the right eye. The sclera was supported with a Flieringa ring and a $7.0 \mathrm{~mm}$ graft was placed in a $6.5 \mathrm{~mm}$ host bed. The donor button was secured with 16 interrupted 10-0 nylon sutures. She had an uneventful postoperative course and was placed on Pred-G (prednisolone) ointment in the left eye four times
Accepted for publication 1 May 1997 


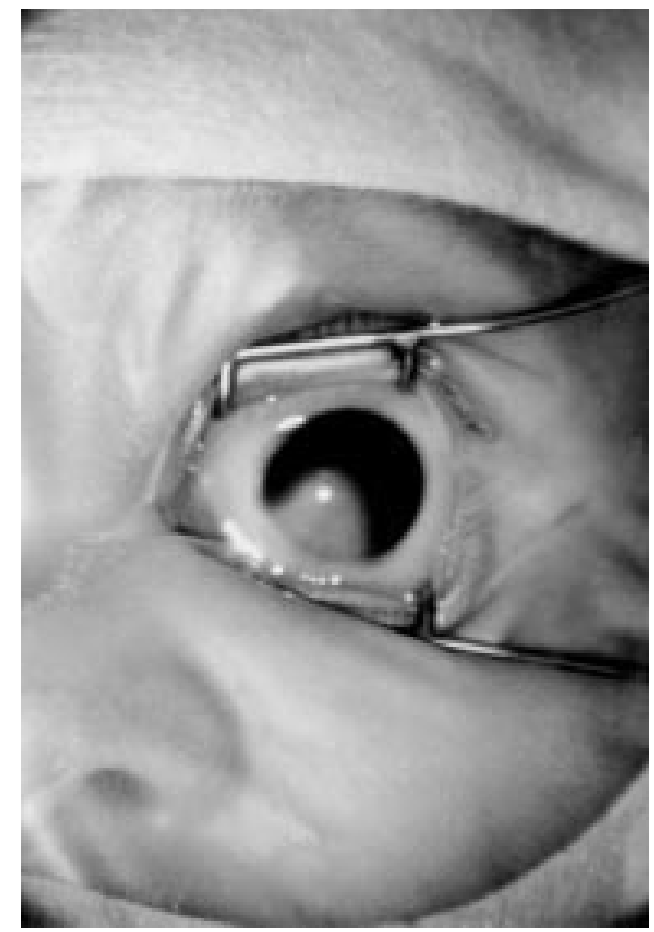

Figure 1 Right eye (photograph developed from negative in reverse) of patient $\mathcal{F} G$ at 19 days of age showing corneal opacification present before surgery.

daily and atropine $0.5 \%$ left eye twice daily. The parents were instructed to begin patching the left eye 4-5 waking hours a day.

Pathological analysis of the corneal button removed during surgery showed disorganisation of stromal lamellae with scattered vessels and absence of Descemet's membrane within the area of stromal opacification, consistent with a diagnosis of corneal dysgenesis.

On 3 April 1990 the patient had an uncomplicated repair of her cardiovascular abnormality. She was examined on 13 April 1990 and she had fixation with poor following in both eyes but central steady and maintained (CSM) gaze in both eyes The graft was thin, clear, and completely epithelialised without vascularisation. Refraction was $+1.00+1.00 \times 10$ in the right atropinised eye. Pred-G ointment, atropine, and patching were continued.

She returned for examination on 11 May 1990 with CSM gaze in both eyes and no change in the ocular examination except a small angle esotropia. The cycloplegic refraction was $+1.75+2.25 \times 35$ right eye and +1.75 sphere left eye She was scheduled for examination under anaesthesia and suture removal and the parents were instructed to continue with patching, atropine, and Pred-G ointment.

Because of a difficult family environment with the child being transferred to foster care she was not examined again until 20 June 1990. She was now on no medicines and had was not being patched. She had CSM gaze in both eyes with a small angle esotropia. The graft was clear and compact with a single vessel entering superficially for about $0.5 \mathrm{~mm}$ inferonasally. Some sutures were loose. The patient was again scheduled for examination and suture removal.
She did not return again until 6 August 1990 at which time she underwent an examination under anaesthesia. Her intraocular pressure was $6.0 \mathrm{~mm} \mathrm{Hg}$ in both eyes under light anaesthesia with pneumotonography. Her corneal diameters were $10.0 \mathrm{~mm}$ horizontal $(\mathrm{H})$ by 9.0 $\mathrm{mm}$ vertical $(\mathrm{V})$ right eye and $10.5 \mathrm{~mm} \mathrm{H}$ by $9.5 \mathrm{~mm} \mathrm{~V}$ left eye There was ciliary injection in the right eye. The graft had an endothelial rejection line from the 5:00 position to the 10:00 position with stromal and epithelial oedema occupying the inferolateral half of the graft. There were vessels around two sutures at the 5 o'clock and 6 o'clock positions from the host cornea into the graft superficially. All sutures were removed at this time. The anterior chamber, lens, vitreous, and fundus examination was normal. A subconjunctival injection of Decadron (dexamethasone) $5 \mathrm{mg} / 0.5 \mathrm{ml}$ was given. The foster parents were instructed to instil prednisolone acetate $1 \%$ solution in the right eye every hour during the day and Pred-G ointment at night.

On 21 August 1990 she returned with a thin, clear graft and no evidence of rejection. Her cycloplegic refraction was $+3.50+2.25 \times 65$ right eye and $+4.00+1.75 \times 180$ left eye. She was continued on a tapering regimen of steroid drops. On 26 September 1990 she had a stable examination with CSM gaze and orthophoria at near and a clear graft. Teller grating acuity cards were performed for the first time and showed approximate Snellen acuities to be 20/300 right eye (one octave below normal for age) and 20/200 left eye (normal for age). The parents were instructed to stop the steroid drops and patch the left eye all but 1 hour a day and return in 2 weeks.

On 19 December 1990, now 10 months old, she returned and her examination was unchanged except for the appearance of typical congenital nystagmus and a small angle intermittent esotropia. The graft was clear and her cycloplegic refraction was $+2.00+3.00 \times$ 85 right eye and $+1.00+1.75 \times 95$ left eye. Her parents were given a prescription for glasses and instructed to continue patching the left eye for half her waking hours.

She did not return for evaluation until 13 May 1991, now 15 months old. She was on no ocular medicines. She had CSM gaze in both eyes with an 18-20 prism dioptres esotropia and a left eye preference on cover/uncover testing. She also had bilateral dissociated vertical deviation, overaction of the inferior obliques, and a nystagmus pattern typical of congenital nystagmus with a latent component or manifest latent nystagmus. The graft was thin and clear without any evidence of new vascularisation, scarring, or rejection. The remainder of her examination was normal. A cycloplegic refraction was $+2.00+1.00 \times 90$ right eye, $+3.00+0.50 \times 160$ left eye. Teller grating acuity showed Snellen equivalents of 20/150 right eye and 20/100 left eye (normal for age in both eyes). A prescription for glasses and instructions to continue patching the left eye for half her waking hours was given to the parents.

On 3 July 1991, 21 August 1991, and 30 October 1991 the only change in her clinical 


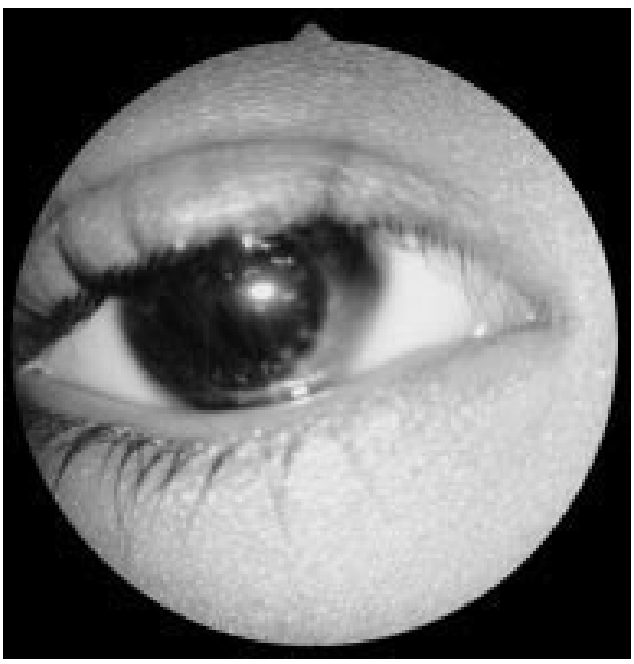

Figure 2 Right eye of patient $\mathcal{F} G$ at 6 years of age showing clear, thin, avascular corneal graft.

examination was a small angle esophoria at near with her glasses in place. The graft was clear and the Teller acuity cards measurements, nystagmus, overaction of her oblique muscles, and dissociated vertical deviation (DVD) had not changed. Glasses and occlusion of the left eye were continued.

Her last examination was on 22 March 1996, at which time she was 6 years of age. Visual acuity measured with Snellen optotypes was 20/30 right eye and 20/40 left eye She had a small angle esotropia with a preference for her right (grafted) eye. Her graft was thin and clear (Fig 2). She had an 18-20 prism dioptres esotropia with her correction in place at near. Cycloplegic refraction changed to $-0.75+2.00$ $\times 90$ right eye and $+2.00+1.00 \times 180$ left eye. The remainder of her examination was unchanged. She was given a new glasses prescription and patching of the right eye was instructed for 6-8 hours a day.

CASE 2

MB was the $8 \mathrm{lb} 3 \mathrm{oz}(3714 \mathrm{~g}$ ) white male full term product of a 31-year-old white female who had an uncomplicated pregnancy, labour, and delivery. He was first evaluated by us at 5 days of age for a corneal opacification of the left eye. His initial examination was significant for an opaque vascularised central corneal lesion measuring approximately $4 \mathrm{~mm}$ in diameter (Fig 3). No red reflex was visible with the pupil undilated. The remainder of the ophthalmic examination was normal in both eyes. Cycloplegic refraction of the right eye was +3.00 sphere.

On 3 March 1990, at 15 days of age the patient underwent a $7.0 \mathrm{~mm} / 7.5 \mathrm{~mm}$ uneventful penetrating keratoplasty of the left eye. Sixteen 10-0 nylon sutures were used to secure the donor to the host bed. The patient was placed on prednisolone acetate $1 \%$ solution every 6 hours, atropine $0.5 \%$ solution every 12 hours, and gentamicin $0.3 \%$ solution every 6 hours.

Pathological analysis of the corneal button removed at surgery showed thickening of the

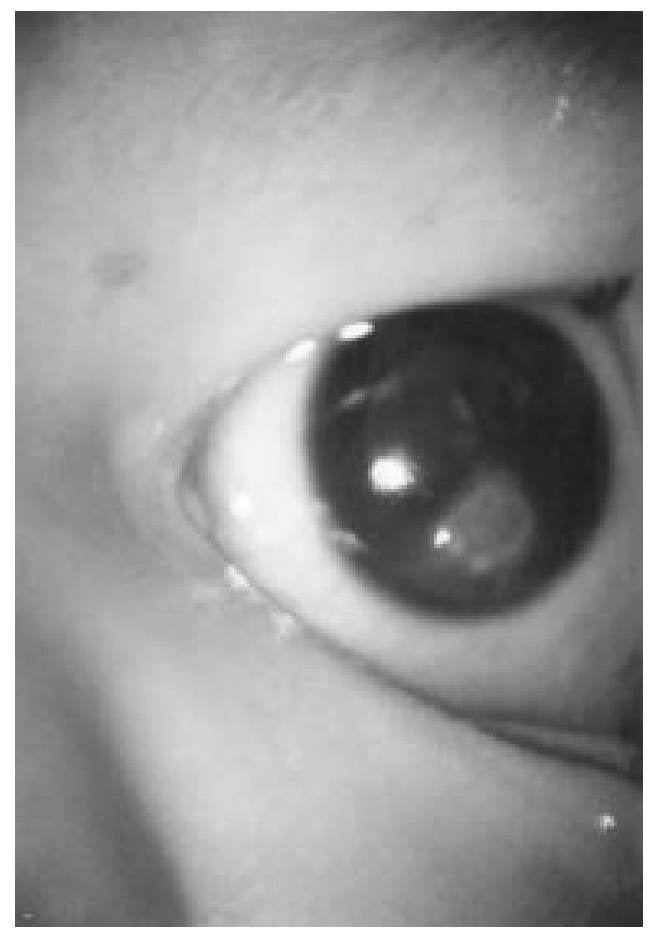

Figure 3 Left eye of patient MB at 15 days of age showing corneal opacification present before surgery.

epithelium with fibrosis and vascularisation in the superficial stroma.

The patient was examined on 5 March 1990, 9 March 1990, and 16 March 1990 with a thin, clear, and epithelialised graft. A refraction on 9 March 1990 was +3.25 sphere right eye and +4.00 sphere left eye. Patching of the right eye 3-4 hours a day was started on 16 March 1990. Examinations on 23 March 1990, 30 March 1990, 6 April 1990, and 13 April 1990 showed the graft to be thin and clear with the wound secure and no neovascularisation. Visual examination showed positive optokinetic responses in both eyes. Cycloplegic refraction on 6 April 1990 was +4.00 sphere right eye and $+3.00+2.00 \times 150$ left eye. Topical atropine and gentamicin were discontinued and the prednisolone acetate was decreased to every 8 hours. Patching of the right eye was increased to half of the patient's waking hours.

On 19 April 1990 an examination under anaesthesia and suture removal was performed. Pneumotonometry under light anaesthesia was $15 \mathrm{~mm} \mathrm{Hg}$ right eye and $12 \mathrm{~mm} \mathrm{Hg}$ left eye. The corneal diameter was $11.0 \mathrm{~mm}$ in both eyes. The graft was thin and clear with one superficial vessel near the wound centred around a suture at 10:00. Eight of 16 sutures were removed. The remainder of the examination for both eyes, including slit lamp, gonioscopy, and fundus examination was normal. Gentamicin $0.3 \%$ and prednisolone acetate $1 \%$ solutions were used every 6 hours.

Examinations were performed on 26 April 1990, 11 May 1990, and 18 May 1990. The patient discontinued the gentamicin and had the topical steroid tapered to twice daily and was patching the right eye for half his waking hours. Vision had improved to fixation and following with CSM gaze in both eyes. The 
patient was orthophoric at near, and the graft was clear and compact. A cycloplegic refraction on 11 May 1990 was $+3.00+0.75 \times 90$ right eye and $-0.50+2.00 \times 180$ left eye. The first Teller grating acuity was performed on 18 May 1990 and showed Snellen equivalents of 20/1600 right eye and 20/1200 left eye (below normal for age in both eyes).

On 18 May 1990 and 17 July 1990 the patient returned on topical prednisolone acetate $1 \%$ twice daily and half time patching. The graft was thin and clear without neovascularisation and had half the sutures remaining. The overall corneal diameter increased and the refraction was now $+3.00+0.50 \times 90$ right eye and $-11.00+10.50 \times 180$ left eye. There was slight optic nerve cupping on the left eye compared with the right. The patient was not photophobic or tearing. Increased intraocular pressure in the left eye was suspected either secondary to associated congenital glaucoma or in response to topical steroids.

On 20 July 1990 the patient underwent examination under anaesthesia and suture removal. Intraocular pressure was $17 \mathrm{~mm} \mathrm{Hg}$ right eye and $25 \mathrm{~mm} \mathrm{Hg}$ left eye with pneumotonometry under light anaesthesia. Corneal diameter was $12.0 \mathrm{~mm}$ horizontal $(\mathrm{H})$ by 11.5 $\mathrm{mm}$ vertical $(\mathrm{V})$ right eye and $12.5 \mathrm{~mm} \mathrm{H}$ by $12.0 \mathrm{~mm}$ V left eye. Axial length was $19.57 \mathrm{~mm}$ right eye and $20.35 \mathrm{~mm}$ left eye. The graft was thin and clear and the wound appeared healed. The sutures were removed. The remainder of the examination was normal with the cup/disc ratio 0.1 right eye and 0.2 left eye. Topical steroids were discontinued and the patient was fitted with a blue, $\mathrm{RD} 4$ Boston contact lens in the left eye with a base curve 7.62 , power -5.87 , central thickness 15 , diameter $8.5 \mathrm{~mm}$. Patching of the right eye was increased to all but 1 waking hour a day.

The patient was examined on 20 August 1990 and 27 September 1990 without any change. He was tolerating daily removal of the contact lens well although several lenses had been lost and replaced.

The patient was examined under anaesthesia again on 11 February 1991. The intraocular pressure was $15 \mathrm{~mm} \mathrm{Hg}$ in both eyes and the corneal diameters had not changed from the previous examination under anaesthesia. The graft was clear and the remainder of the examination was normal in both eyes

The patient has been examined regularly since 11 February 1991. The graft has remained clear, thin, without neovascularisation or any episode of rejection (Fig 4). The refraction has changed slightly and on examination on 7 March 1992 it was +1.00 sphere right eye and $-7.50+9.50 \times 180$ left eye. He is wearing a Softperm lens with a base curve of 7.50, 14.3 diameter, and -2.00 power. With this lens in place he has a +1.00 over-refraction after cycloplegia. Clinical evaluation on 7 March 1992 at 24.5 months of age showed fixation and following with CSM gaze in both eyes. His last examination on 26 March 1996, at 6 years 1 month of age, showed a visual acuity of 20/20 left eye using Snellen optotypes with the contact lens in place. He has remained

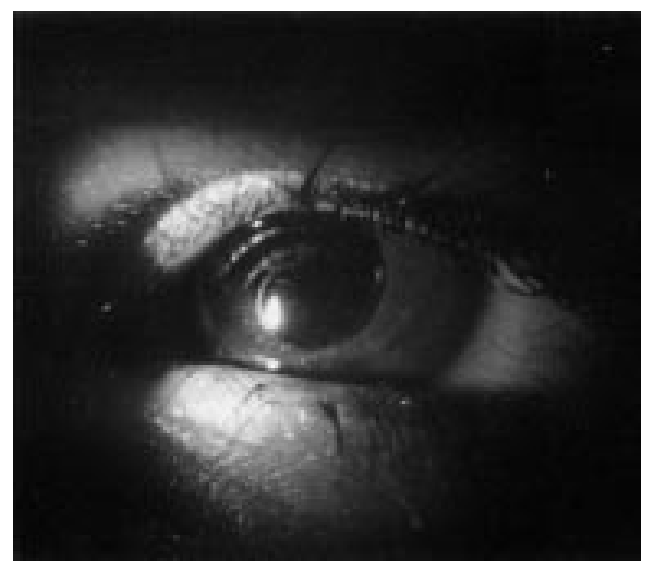

Figure 4 Left eye of patient $M B$ at 6 years of age showing clear, thin, avascular corneal graft.

orthophoric in all positions of gaze at distance and near with alternate cover testing. He had a negative 10 prism dioptres test but a positive 4 prism dioptres base out test of the left eye. The remainder of the examination was normal.

\section{Discussion}

These two cases are unique for many reasons. They both had isolated central corneal opacification as their only ocular abnormality. They were both secondary to a non-progressive developmental abnormality. ${ }^{5}$ Penetrating keratoplasty was performed during the neonatal period and both grafts have survived over 6 years. Optical rehabilitation and amblyopia treatment were consistent and immediately instituted. One graft had one rejection episode which was successfully treated and probably secondary to associated neovascularisation. One graft has a high amount of residual astigmatism.

One patient has developed the infantile esotropia syndrome which we believe is unrelated to the graft. She has developmental delay, a seizure disorder, a congenital cardiac malformation, and a positive family history of strabismus. All these conditions are associated with a higher incidence of strabismus.

Clinical evaluation of visual acuity showed evidence of amblyopia in the grafted eyes but objective measurement using the Teller grating acuity cards and recently HOTV optotypes shows that vision in both grafted eyes is within normal limits for age.

Several aspects of the neonatal immune system may enhance graft survival. The immune system of humans originates very early in gestation and is extensively developed by birth. ${ }^{19}$ Differences in the neonatal immune system include (1) $10 \%$ of normal adult IgG and IgM, (2) no serum IgA, (3) no mucosal IgA until 2 weeks of life, (4) a dominance of suppressor $\mathrm{T}$ cell function, and (5) quantitatively normal but qualitatively less $\mathrm{B}$ cell function. ${ }^{20-22}$ The phenomena that characterise the immune response of the neonate relate to the immaturity of cellular interactions rather than to the absence or incapacity of a single cell line.

General conditions favouring induction of tolerance include immunological immaturity, alteration of the host by irradiation, drugs, and 
antilymphocyte globulin, the administration of orally administered antigen, the purification and preparation of antigen in monomeric or deaggregated form, and transplantation into privileged sites. $^{23}$

It is well known that the anterior chamber of the eye is a privileged site for transplantation. ${ }^{23}$ This is in large part the result of the absence of a blood supply and access to the lymphatic system for the presentation of foreign antigens to the immune system as part of the afferent arc of rejection. The neonatal period is a time of immunological immaturity which is predisposed to immune tolerance secondary to less effective cooperation of the cellular and humoral components. ${ }^{20-23}$ It is known that there is no difference in renal allograft survival between infants and adults, although most transplants are performed after the neonatal period. ${ }^{23}$ Several animal experiments and human observations have shown the unique susceptibility of neonatal splenic B cells for induction of tolerance. ${ }^{21-23}$ Recommendations for immunisation schedules in neonates avoid the first 4 weeks of life because of the possible development of tolerance to subsequent doses of antigen and less than optimal future antibody responses. ${ }^{24}$

Paediatric penetrating keratoplasty has largely been an ineffective surgical procedure. Problems particular to the paediatric population include (1) technical difficulties secondary to a small eye, low scleral rigidity, other associated ocular abnormalities (cataracts, glaucoma, microphthalmia), and an exuberant inflammatory response; (2) immaturity of the visual system, and (3) family compliance with medical treatment, timely follow up, and amblyopia therapy. ${ }^{1-8}$ In a recent multicentre study of paediatric keratoplasty the authors found that after an average follow up of 4 years $62 \%$ of all grafts were clear, $19 \%$ were hazy, and $19 \%$ were opaque. ${ }^{8}$ Of all patients, vision better than or equal to counting fingers was present in $60 \%$. They found that congenital opacities were just as likely to have a clear graft at 1 year as acquired opacities. ${ }^{8}$

Most reports describe generally poor visual results after penetrating keratoplasty in childhood. ${ }^{2-7}$ This has led to written recommendations suggesting conservative treatment. ${ }^{15}$ Although we agree that many problems exist with congenital corneal transplantation and the majority result in poor visual results, selected cases performed in the neonatal period may be more successful.

It may be that in these selected cases graft survival is reasonable. Specifically, isolated corneal abnormalities grafted in the neonatal period may have a better prognosis. Neonatal immune tolerance and visual rehabilitation during the most sensitive period of visual development are probably the primary factors responsible for the success of these grafts. It is our hope that this report will stimulate further study involving neonatal penetrating keratoplasty.

1 Moore TE. Keratoplasty. In: Corneal disorders, clinical diagnosis and management, Leibowitz HM, ed. Philadelphia: WB Saunders, 1984:514-25.

2 Waring GO, Laibson PR. Keratoplasty in infants and children. Trans Am Acad Ophthalmol Otolaryngol 1977;83: 283-6.

3 Stulting RD, Sumers KD, Cavanagh HD, Waring GO 3d, Gammon JA. Penetrating keratoplasty in children. Ophthalmology 1984;91:1222-4.

4 Brown SI. Corneal transplantation of the infant cornea. Trans Am Acad Ophthalmol Otolaryngol 1974;78:461-2.

5 Beauchamp GR. Pediatric keratoplasty: problems in management. F Pediatr Ophthalmol Strabismus 1979;16:388-91.

6 Schanzlin DJ, Goldberg DB, Brown SI. Transplantation of congenitally opaque corneas. Ophthalmology 1980;87: $1253-5$

7 Noble BA, Easty DL. Late corneal grafting in congenitally opaque corneas. Dev Ophthalmol 1985;11:75-8.

8 Dana MR, Moyes AL, Gomes JAP, Dua HS, Goren MB. The indications for and outcome in pediatric keratoplasty. Ophthalmology 1995;102:1129-38.

9 Wiesel TN. Postnatal development of the visual cortex and the influence of the environment. Nature 1982;299:583-91.

10 Hubel DH, Weisel TN. The period of susceptibility to the physiologic effects of unilateral eyelid closure in kittens. $\mathcal{F}$ Physiol (Lond) 1970;206:419-36.

11 von Noorden GK. Mechanisms of amblyopia. Adv Ophthalmol 1977;34:92-115.

12 Vaegan, Taylor D. Critical periods for deprivation amblyopia in children. Trans Ophthalmol Soc UK 1980;9:432-9.

13 Teller DY, Movshon JA. Visual development. Vision Res 1986;6:1483-506.

14 Mayer DL, Dobson DC. Visual acuity development in infants and young children as assessed by preferential looking. Vision Res 1982;22:1141-51.

15 Jacobson SG, Mohindra I, Held R. Age of onset of amblyopia in infants with congenital esotropia. Doc Ophthalmol 1981;30:210-6.

16 Dobson V, Teller DY. Visual acuity in human infants: a review and comparison of behavioral and electrophysiological studies. Vision Res 1978;18:469-83.

17 Boothe RG, Dobson V, Teller DY. Postnatal development of vision in human and nonhuman primates. Annu Rev Neurosci 1985;8:495-545.

18 Taylor DM, Vaegan, Morris JA, Rogers JE, Warland J. Amblyopia in bilateral infantile and juvenille cataract. Trans Ophthalmol Soc UK 1979;99:170-5.

19 Gill TJ, Rabin BS, Kunz HW, Davis BK, Taylor F. Immunologic aspects of maternal-fetal interactions. In: Cooper $\mathrm{MD}$, Dayton DH, eds. Development of host defenses. New York: Raven Press, 1977:287-302.

20 Sites DP, Caldwell J, Carr MC, Fudenburg HH. Ontogeny of immunity in humans. Clin Immunol Immunopath 1975;4: 519-27.

21 Lawton AR, Cooper MD. Ontogeny of immunity. In: Stiehm ER, Fulginiti VA, eds. Immunologic disorders in infants and children. Philadelphia: WB Saunders, 1980:3649

22 Hayward AR. Development of immune mechanisms. In: Soothill JF, Hayward AR, Wood CBS, eds. Pediatric immunology. Oxford: Blackwell Scientific, 1983:48-55.

23 Buckley RH. Transplantation. In: Stiehm ER, Fulginiti VA, eds. Immunologic disorders in infants and children. eds. Immunologic disorders in infants
Philadelphia: WB Saunders, 1980:776-804.

24 Garber RM, Mortimer EA. Immunizations. Beyond the basics. Pediatrics in Review 1992;13:98-106. 